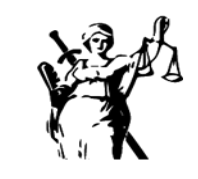

JUSTICIA

ISSN impreso 0124-7441
ISSN digital 2590-4566

\title{
Obligaciones de los estados respecto de la protección de los dere- chos humanos: en el trabajo y la seguridad social
}

\author{
Obligations of the states regarding the protection of human rights: at work \\ and social security
}

\author{
Juan Manuel Ávila Silva \\ Universidad Autónoma del Estado de Morelos, México \\ licjuanmanuelavila@hotmail.com
}

Gabriela Mendizábal Bermúdez

Universidad Autónoma del Estado de Morelos, México

mgabriela@uaem.mx

Recibido: 14 de octubre de 2019 / Aceptado: 14 de diciembre de 2019

https://doi.org/10.17081/just.25.37.3911

\begin{abstract}
Resumen
El objetivo del presente artículo fue demostrar que los Estados deben adecuar su legislación interna con el contenido de los instrumentos internacionales que reconocen derechos humanos en el trabajo y la seguridad social. La metodología utilizada fue analítica-deductiva en donde se estudiaron en el ámbito Latinoamericano la aplicación de las declaraciones, cartas, protocolos, mismos que resultaron de observancia obligatoria y tienen un carácter vinculante para los Estados, de acuerdo con los criterios interpretativos de la Corte Interamericana de Derechos Humanos, caso contrario puede ocasionar responsabilidades indirectas por violaciones a este tipo de derechos. Estos derechos parten de la dignidad del trabajador, ya que, al iniciar, una relación laboral sea de carácter estatal o privada, tienen derecho a un salario remunerado, a la libertad sindical, a no realizar trabajo forzoso, a no ser discriminado, a contar con el derecho a formación profesional, a una protección social adecuada, aunado a los mecanismos que garanticen estos derechos.
\end{abstract}

Palabras clave: Derechos sociales, protección, interpretación, obligacione, estados.

\begin{abstract}
The objective of this paper was to demonstrate that States must adapt their domestic legislation to the content of international instruments that recognize human rights at work and social security. The methodology used was analytical-deductive in which the application of declarations, letters, protocols, which were mandatory and binding on the States, were studied in the Latin American context, in accordance with the interpretive criteria of the Inter-American Court. of Human Rights, otherwise it may cause indirect responsibilities for violations of this type of rights. These rights start from the dignity of the worker, since, at the beginning, an employment relationship is of a state or private nature, they have the right to a remunerated salary, to freedom of association, not to perform forced labor, not to be discriminated against, to have with the right to professional training, to an adequate social protection, together with the mechanisms that guarantee these rights.
\end{abstract}

Keywords: Social rights, protection, interpretation, obligations, States.

\section{Como citar:}

Ávila Silva, J. M., \& Mendizábal Bermúdez, G. (2020). Obligaciones de los Estados respecto de la protección de los derechos humanos: en el trabajo y la seguridad social. Justicia, 25(37), 21-34. https://doi.org/10.17081/just.25.37.3911 


\section{Introducción}

إح I tema aquí estudiado, cobra relevancia a partir del reconocimiento de los derechos humanos por parte de los Estados en sus constituciones. Sin embargo, se requiere el cumplimiento de otras obligaciones, por parte de estos para lograr su plena protección.

Por lo que surgen las siguientes interrogantes ¿cuáles son las obligaciones que tienen que cumplir los Estados respecto de las declaraciones protocolos, cartas que contienen derechos humanos en el trabajo y la seguridad social? ¿Son vinculantes jurídicamente o son solo documentos declarativos?

Las declaraciones, cartas, protocolos resultan de observancia obligatoria, y más aún los Estados tienen la obligación de armonizar los contenidos de estas, así como de los instrumentos internacionales a su legislación interna, caso contrario puede ocasionar responsabilidades indirectas por violaciones al corpus juris internacional en derechos humanos.

El objetivo es demostrar que los Estados deben adecuar su legislación interna con lo dispuesto por los instrumentos internacionales que contienen estos derechos, por ser vinculantes.

Derivado de lo anterior, en este artículo a través de una metodología analítica, deductiva se estudian estos derechos en el ámbito Latinoamericano, se conocen diferentes posturas teóricas que abonan a la protección de estos derechos, así como los criterios de interpretaciones por parte de la CIDH, de donde se advierte la tendencia para su protección, imponiendo obligaciones directas e indirectas a los Estados que son importantes conocer; así, se analizó por orden metodológico: primero, el marco conceptual de los derechos humanos en el trabajo y la seguridad social; segundo, se estudian estos derechos en instrumentos internacionales en Latinoamérica, tercero, se analiza su protección desde ámbito internacional, dando paso a conclusiones y fuentes de investigación.

\section{Derechos humanos en el trabajo y la seguridad social}

Para empezar el concepto de los derechos humanos tiene una "dimensión multidimensional que conlleva tres dimensiones o discursos: el filosófico (donde surge); el político (donde adquiere consenso); y, el jurídico (que lo introduce al ámbito de la legalidad y busca dotarlo de eficacia)" (Álvarez, 2015, p.39).

De ahí que analizamos la dimensión jurídica, pues se busca conocer:

¿Cuáles son los elementos para hacer eficaces estos derechos? Pon tanto se da paso al estudio del concepto de derechos humanos no sin antes realizar las siguientes precisiones terminológicas.

Basados en el análisis de Carpizo (2011):

La relación entre derechos humanos y derechos fundamentales sería que los primeros implican un mayor matiz filosófico, guardan una connotación prescriptiva y deontológica, y aún no han sido objeto de recepción del derecho positivo, mientras que los derechos fundamentales son los derechos y libertades reconocidos y garantizados por el derecho positivo de los Estados, y, para algunos autores por el derecho internacional de los derechos humanos (p.14).

Se considera que esta aclaración resulta trascendental en el presente trabajo ya que de acuerdo con Carpizo (2011) estos derechos son sinónimos (p.15). Por lo que en el presente estudio se utilizará el término de derechos humanos y/o derechos fundamentales indistintamente. 
Ahora bien, al respecto para Ferrajoli (2004):

Son «derechos fundamentales» todos aquellos derechos subjetivos que corresponden universalmente a «todos» los seres humanos en cuanto dotados del status de personas, de ciudadanos o personas con capacidad de obrar; entendiendo por «derecho subjetivo» cualquier expectativa positiva (de prestaciones) o negativa (de no sufrir lesiones) adscrita a un sujeto por una norma jurídica; y por «status» la condición de un sujeto, prevista asimismo por una norma jurídica positiva, como presupuesto de su idoneidad para ser titular de situaciones jurídicas y/o autor de los actos que son ejercicio de éstas (p.37).

Así, el referido autor plantea acerca de estos derechos subjetivos a prestaciones o no sufrir lesiones, establecidos en una norma jurídica positiva, en donde se reconoce la condición de la persona para ser titular y autor de los actos para ejercerlas. Las expectativas positivas o negativas que tienen las mismas para ejercer esos derechos, previstos en la ley, como presupuestos para ser titular y autor de actos jurídico.

De los cuáles encontramos que los derechos implican expectativas de actuar por parte del Estado, a través de la generación de legislación y en muchos casos políticas públicas para lograr su materialización.

Por su parte para Sánchez (2008):

El derecho de toda persona al trabajo, de llevar una vida digna de acuerdo con la dignidad humana -trabajo forzoso, libertad sindical y no discriminación-, a una formación profesional de por vida y de contar con una protección social adecuada. Derechos que pueden ser considerados como fundamentales en la medida que se caracterizan por su universalidad, transnacionalidad, irreversibilidad, progresividad y consensualidad (p.674).

Es importante destacar que los principios en que descansan los derechos humanos que aquí se tratan, también se encuentran caracterizados por su universalidad, interdependencia, indivisibilidad y progresividad.

Y en relación a los derechos fundamentales de los trabajadores, podemos señalar que son:

aquellos que protejan la dignidad y la igualdad de los trabajadores. Ya que, al momento de prestar un servicio personal subordinado, sus libertades se ven afectadas, dado por la relación de trabajo que existe con su patrón, al ser este último el controlador y fiscalizador del trabajo que realice precisamente el trabajador. (Mendizábal y Jiménez 2012, p.181).

Por lo que se puede afirmar que la dignidad es el valor más importante, a través del cual se deben desarrollar las relaciones laborales en un sistema jurídico garante de los derechos humanos, y que estos irradian su protección logrando la igualdad y protegiendo las libertades de los trabajadores.

Patricia Kurczyn (s.f.) nos dice:

La seguridad social es un derecho humano; forma parte del grupo de los llamados derechos sociales, de los derechos prestacionales que se identifican con el Estado de bienestar o el Estado social de derecho. Su inclusión en los textos de las leyes fundamentales resulta incondicional (p.204).

De lo anterior, se puede señalar que todo trabajador al iniciar una relación laboral, tienen derechos fundamentales en el trabajo a saber: a un salario remunerador, la libertad sindical, a no realizar trabajo forzoso, a no ser discriminado, a contar con el derecho a una formación profesional, asi como una protección social adecuada, entendida esta como el acceso a los sistemas de seguridad social; así como los mecanis- 
mos de garantía de estos derechos, lo anterior tomando como punto de partida la dignidad del trabajador.

Sin embargo, los derechos sociales a prestaciones públicas positivas no se ha visto acompañada de la elaboración de garantías sociales o positivas adecuadas, es decir, de técnicas de defensa y de justiciabilidad parangonables a las aportadas por las garantías liberales o negativas para la tutela de los derechos de libertad (Ferrajoli, 2004, p. 64).

Por lo que es importante para lograr la efectividad de estos derechos, dotarlos de mecanismos que garanticen su pleno cumplimiento en los marcos normativos constitucionales y secundarios, ya que en algunos casos se cuenta con su reconocimiento, pero, se encuentran ausentes los mecanismos antes señalados.

Por su parte Pérez Luño (2005) ha planteado respecto de los derechos humanos de corte individual y social, que existe:

La complementariedad reciproca que en el terreno de la fundamentación asumen ambas categorías de derechos es corolario de la necesaria intervención estatal para su realización efectiva; intervención que ha ido unida al progresivo reconocimiento de los derechos sociales. De ahí que si el reconocimiento de los derechos individuales supone una garantía frente al absolutismo del Estado, que sino sitúa como fin de su política social la libertad, degrada los derechos de sus ciudadanos a simples intereses objetos de protección en cuanto sean acordes con los de quienes ejercen el poder; la proclamación de los derechos sociales supone una garantía para la democracia, esto es, para el efectivo disfrute de las libertades civiles y políticas (p.28).

Se puede afirmar válidamente que los derechos humanos de corte social, resultan ser complementarios a los individuales, contribuyendo al logro efectivo de las libertades civiles, políticas y sociales de las personas, incluso se vuelven una condición necesaria dentro de un estado democrático, en donde se garantizan las libertados civiles y políticas, pero, sobre todo las sociales.

De lo anterior tenemos que al ser humano se le reconocen derechos humanos de carácter social, como serían los derechos en el trabajo y la seguridad social, en los que encontramos que tanto la autoridad; como los particulares, están obligados a respetarlos, teniendo como limite el bien común en una sociedad.

De igual forma Robert Alexy (2000) plantea dos tesis respecto de estos derechos:

La primera reza: la libertad jurídica para hacer u omitir algo sin la libertad fáctica (real), es decir, sin la posibilidad fáctica de elegir entre lo permitido, carece de todo valor [...] el derecho de libertad no tendría valor alguno sin los presupuestos fácticos para poder hacer uso de él. La segunda tesis reza: bajo las condiciones de la moderna sociedad industrial, la libertad fáctica de un gran número de titulares de derechos fundamentales no encuentra su sustrato material en un "ámbito vital dominado por ellos, sino que depende esencialmente de actividades estatales (p.71).

Se considera que ambas tesis se complementan entre sí, respecto de los derechos sociales en razón de que la libertad es el punto de partida, para elegir el trabajo, arte u oficio, lo que da origen a una relación laboral, siendo en este punto en donde entra la actividad estatal, al establecer bajo qué condiciones laborales y de seguridad social, se va a llevar a cabo el desarrollo de la misma.

Por lo que, pueden surgir relaciones laborales entre el Estado y los particulares, también se encuentran las que, el patrón y el trabajador, son particulares; y en ambas podemos afirmar que la protección de los 
derechos humanos sociales, dependerá de la actividad estatal, tanto al crear, como al momento de aplicar las leyes que regulan esas relaciones.

Así tenemos que al hablar de derechos sociales fundamentales Alexy reconoce:

Que se dividen en tres criterios: Primero pueden tratarse de normas que contienen derechos subjetivos o de normas que obligan al Estado solo objetivamente. Pueden, segundo, ser normas vinculantes o no vinculantes y en este sentido ser enunciados programáticos. Una norma será llamada "vinculante" si es posible que su lesión sea constatada por el Tribunal Constitucional Federal. Tercero las normas pueden fundamentar derechos y deberes definitivos o prima facie, es decir, pueden ser principios o regla [...]. La protección más fuerte la otorgan normas vinculantes que garantizan derechos subjetivos definitivos a prestaciones; la más débil, las normas no vinculantes que fundamentan un mero deber objetivo prima facie del Estado a otorgar prestaciones (Alexy, 2000, p.69).

De lo que se puede inferir válidamente, que estos derechos tienen que ser reconocidos como derechos subjetivos, en un sistema jurídico, para logar una eficaz protección de los mismos. Así damos paso a su estudio en instrumentos internacionales.

\section{En instrumentos internacionales de Latinoamérica}

De otra parte, los derechos humanos sociales cobran trascendencia en la actualidad ya que existen diversas declaraciones, instrumentos internacionales, convenciones, protocolos en los que encontramos los derechos humanos de corte social, los cuales estudiamos a continuación.

Como quedo apuntado-en su dimensión política- son reconocidos esos derechos en las declaraciones del siglo XVIII, siendo la más importante la Declaración Universal de los Derechos Humanos, de esta han surgido diversos instrumentos como convenciones, declaraciones y protocolos, asimismo en esta se reconocen los derechos humanos en el trabajo y la seguridad social.

\section{La Declaración Universal de los Derechos Humanos}

La Declaración Universal de los Derechos Humanos ${ }^{1}$ (1948) de la Organización de las Naciones Unidas (ONU), señala en sus artículos 22, 23, 24 y 25 lo siguiente:

El artículo 22 establece, toda persona, como miembro de la sociedad, tiene derecho a la seguridad social, a obtener, mediante el esfuerzo nacional y la cooperación internacional, habida cuenta de la organización y los recursos de cada Estado, la satisfacción de los derechos económicos, sociales y culturales, indispensables a su dignidad y al libre desarrollo de su personalidad.

Así, el artículo 25, señala:

1. Toda persona tiene derecho a un nivel de vida adecuado que le asegure, así como a

1 Esta Declaración es considerada el fundamento de las normas internacionales de derechos humanos, ha inspirado la creación de más de 80 declaraciones y tratados internacionales vinculantes, un gran número de convenciones regionales, proyectos de ley nacionales de derechos humanos y disposiciones constitucionales que, en conjunto, constituyen un sistema amplio jurídicamente vinculante para la promoción y la protección de los derechos humanos. (ONU) Recuperada de :http://www.ordenjuridico.gob.mx/ TratInt/Derechos\%20Humanos/INST\%2000.pdf 
su familia, la salud y el bienestar, y en especial la alimentación, el vestido, la vivienda, la asistencia médica y los servicios sociales necesarios; tiene asimismo derecho a los seguros en caso de desempleo, enfermedad, invalidez, viudez, vejez u otros casos de pérdida de sus medios de subsistencia por circunstancias independientes de su voluntad. 2. La maternidad y la infancia tienen derecho a cuidados y asistencia especiales. Todos los niños, nacidos de matrimonio o fuera de matrimonio, tienen derecho a igual protección social.

Por tanto, los artículos 22 y 25, reconocen el derecho humano a la seguridad social. El artículo 23 de la misma declaración reconocen el derecho al trabajo, a la libre elección de este, a condiciones equitativas, protección contra el desempleo, a no sufrir discriminación salarial, el derecho humano a una remuneración satisfactoria, así como el derecho a crear y formar parte de los sindicatos.

Así el artículo 24 reconoce el derecho humano: al descanso, a la limitación de la jornada de trabajo, a vacaciones pagadas, el derecho al trabajo, a condiciones laborales equitativas, igualdad salarial, salario satisfactorio, limitación de la jornada, descanso, vacaciones pagadas, así como a formar y ser parte de los sindicatos.

La Declaración Universal de Derechos Humanos "en realidad no es simplemente una declaración, muy a pesar de sus propias denominaciones, pues es nada menos que el documento fundante de todos los tratados internacionales existentes en materia de derechos humanos en el mundo" (Ruiz Moreno y Ruiz Buenrostro, 2017, p.30), ahí su importancia y trascendencia para afirmar válidamente que los derechos que aquí se estudian son derechos humanos y tienen un carácter vinculante como se expondrá más delante.

\section{Carta Internacional Americana de Garantías Sociales}

Se creó en Río de Janeiro, Brasil, 1947, declara los derechos mínimos de los trabajadores en los Estados americanos.

En donde se establecen en diversos artículos, principios básicos en el derecho social, entre los que destacan: el trabajo goza de la protección especial del Estado y no debe ser considerado como artículo de comercio; reconociendo las condiciones justas al trabajador; protege el trabajo intelectual, técnico y manual; reconoce la igualdad de trato y de salario; así como la irrenunciabilidad de los derechos de los trabajadores.

La ley regulará, el contrato individual de trabajo, a efecto de garantizar los derechos de los trabajadores, reconocerá y reglamentará los contratos y convenciones colectivos de trabajo. Regirán en las empresas que hubieren estado representadas en su celebración no solamente para los trabajadores afiliados a la organización profesional que los suscribió; sino para los demás trabajadores que formen parte o lleguen a formar parte de esas empresas.

Por su parte esta Carta, establece el deber del Estado de proveer en beneficios de los trabajadores de previsión y seguridad sociales, los trabajadores...tienen derecho a un sistema de seguro social obligatorio....deberá tender a la protección social de los miembros de la familia del trabajador. Cabe señalar que los empleados públicos tienen derecho a los beneficios de la seguridad social,y que estos se extienden al contrato de aprendizaje.

De igual forma se reconoce que, en los países donde aún no exista un sistema de seguro o pre- 
visión social, o en los que existiendo éste, no cubra la totalidad de los riesgos profesionales y sociales, estarán a cargo de los empleadores prestaciones adecuadas de previsión y asistencia.

Finalmente se reconoce que cada Estado debe existir una jurisdicción especial de trabajo y un procedimiento adecuado para la rápida solución de los conflictos. Así como el deber del Estado de promover la conciliación y el arbitraje como medios para la solución pacífica de los conflictos colectivos de trabajo (Carta Internacional Americana de Garantías Sociales, 1947, artículos 6,7, 28,31,24,20,32, 36 y 37).

\section{Declaración Americana de los Derechos y Deberes del Hombre}

Esta Declaración fue aprobada en la Novena Conferencia Internacional Americana en Bogotá, Colombia en 1948, en donde se reconocen los derechos humanos para el continente americano, siendo de carácter general.

En esta se reconoce en su artículo XIV, el derecho al trabajo y una justa retribución, que aseguren un nivel de vida conveniente al trabajador y a su familia.

De igual forma en esta Declaración se reconoce que, toda persona tienen derecho a la seguridad social que le proteja contra las consecuencias de la desocupación, de la vejez y de la incapacidad que, proveniente de cualquier otra causa ajena a su voluntad, la imposibilite física o mentalmente para obtener los medios de subsistencia. (Declaración Americana de los Derechos y Deberes del Hombre, 1948, artículos XIV y XVI)

De entrada, no parece tener valor vinculante para los Estados, esto está siendo superado por la aplicación que de esta se realiza, en razón de que:

\footnotetext{
En casos contenciosos recientes, la Corte Interamericana también ha hecho uso de la Declaración Americana de Derechos y Deberes del Hombre, en el inicio de un camino de conceptualización de un rubro indemnizatorio para la etapa de reparaciones bajo el nombre de daño al "proyecto de vida". Así, en los casos Loayza Tamayo contra Perú, y Villagrán Morales contra Guatemala, un voto razonado conjunto de los jueces Antonio Cançado Trindade y Alirio Abreu Burrelli sostiene que el proyecto de vida se encuentra indisolublemente vinculado a la libertad, como derecho de cada persona a elegir su propio destino [...] El proyecto de vida se envuelve plenamente el ideal de la Declaración Americana - De los derechos y Deberes del Hombre - de 1948 de exaltar el espíritu como finalidad suprema y categoría máxima de la existencia humana. (Salvioli, s.f. p. 12).
}

De lo que se deduce que la Declaración adquiere valor vinculante de acuerdo al criterio de la CIDH, en los conceptos aplicables en Derechos Humanos del trabajo y la seguridad social, por lo que el criterio, de que la Declaración no parece tener un valor vinculante para los Estados, está siendo superado en la actualidad.

\section{Convención Americana sobre derechos Humanos Pacto de San José Costa Rica de fecha 22 de noviembre de 1969}

Esta convención se adoptó el 22 de noviembre de 1969 en la Ciudad de San José Costa Rica, siendo ratificada por el Estado mexicano el 24 de marzo de 1981, México aceptó el reconocimiento de la competencia contenciosa de la CIDH el 16 de diciembre de 1998. 
En este instrumento se establece, la prohibición de la esclavitud y servidumbre. De igual forma señala que nadie debe realizar trabajo forzoso u obligatorio. No constituye trabajo forzoso el cumplimiento de una sentencia de una autoridad judicial.

En su capítulo III de los Derechos Económicos, Sociales y Culturales, se reconoce la obligación del Estado de impulsar el desarrollo progresivo de los derechos que derivan de normas económicas, sociales, de educación, ciencia y cultura, contenidas en la Carta de Estados Americanos, en la medida de los recursos disponibles (Convención Americana sobre Derechos Humanos, 1969, artículos 6 y 26).

Lo anterior, si bien establece una obligación de progresividad en el desarrollo de las normas sociales, también, se establece la limitante de los recursos disponibles con que cuentan los Estados, lo cual resulta cuestionable atendiendo a la utilización racional de los recursos públicos con que cuentan los Estados, pues no hay que pasar por alto que generalmente la captación de esos ingresos es vía impuestos, y por tanto la sociedad debe beneficiarse de condiciones de trabajo y de seguridad social que impliquen un mínimo vital satisfactoria para sus miembros.

\section{Pacto Internacional de Derechos Económicos, Sociales y Culturales}

Este pacto del cual México forma parte, entró en vigor el 23 de junio de 1981, siendo publicado en el Diario Oficial de la Federación el 12 de mayo de 1981.

Este pacto reconoce, el derecho humano a trabajar, así como la libertad de elegir el trabajo, imponiendo la obligación al Estado de garantizar este derecho. De igual forma se establece que los Estados, deben orientar y promover la formación técnico profesional, así como la preparación de programas, normas y técnicas para conseguir un desarrollo económico, social y cultural, así como la ocupación plena, lo que deberá garantizar tanto las libertades políticas y económicas del ser humano.

Así señala que, los Estados reconocen el derecho de toda persona a condiciones de trabajo equitativas y satisfactorias que les aseguren, una remuneración a todos los trabajadores de un salario equitativo, condiciones de igualdad para las mujeres respecto a los hombres, con un salario igual por trabajo igual. Asimismo condiciones dignas para el trabajador y su familia, en donde se respeta la seguridad y la higiene en el trabajo, derecho a la promoción en su trabajo de acuerdo al tiempo de servicio y capacidad; el descanso, limitación de la jornada de trabajo, vacaciones periódicas pagadas y remuneración de los días festivos.

Asimismo, se establece que, los Estados partes en el Pacto reconocen el derecho de toda persona a la seguridad social, incluso al seguro social (Pacto Internacional de Derechos Económicos, Sociales y Culturales, 1966, artículos 6 punto 1, 6 punto 2, 7 y 9).

De lo que se advierte que el Pacto reconoce el derecho humano al trabajo en condiciones de igualdad, con un salario equitativo, en donde se debe respetar la seguridad y la higiene en el trabajo, reconociendo el derecho a la promoción en el trabajo, también la libertad a elegir el trabajo, así como el derecho humano a la seguridad social.

\section{Protocolo adicional a la Convención Americana sobre derechos Humanos en materia de derechos Económicos, Sociales y Culturales "Protocolo de San Salvador"}

Este protocolo viene a complementar la Convención Americana de Derechos Humanos (Pacto de San José 
Costa Rica) y fue firmado por México el 17 de noviembre de 1988, entrando en vigor el 16 de noviembre de 1999 y publicado en el Diario Oficial de la Federación el 1 de septiembre de 1998.

Se establece el derecho al trabajo, a la libertad de elegir el trabajo; los Estados se comprometen a adoptar las medidas que garanticen el derecho al trabajo, al pleno empleo, a la orientación vocacional, capacitación técnico-profesional, donde se incluyan a los minusválidos, así como el derecho de la mujer a ejercer su derecho al trabajo.

Se reconoce, la obligación de adoptar disposiciones de derecho interno. Si los ejercicios de los derechos establecidos en el presente Protocolo no estuvieran garantizados por disposiciones legislativas o de otro carácter. Los Estados se comprometen a adoptar las medidas legislativas u otras para hacer efectivos los derechos. Por lo que los Estados tienen la obligación de realizar la armonización con el derecho interno, por lo que estos derechos deben ser reconocidos en las constituciones de los Estados, así como en sus normas secundarias.

Por su parte se reconoce que el derecho al trabajo, en el protocolo por parte de los Estados, supone condiciones justas, equitativas y satisfactorias, un salario que asegure condiciones de subsistencia digna, libertad de trabajo, derecho a la promoción o ascenso, la estabilidad del trabajador y en caso de despido injustificado derecho a una indemnización justa o readmisión en el empleo, a contar con seguridad e higiene en el trabajo, prohibición de trabajo infantil, jornada razonable, derecho a vacaciones, descanso, y días feriados pagado.

Asimismo los Estados garantizarán, el derecho de los trabajadores a organizar sindicatos y a afiliarse, se permitirá a los sindicatos formar federaciones y confederaciones nacionales y formar internacionales, los Estados permitirán su libre funcionamiento; se reconoce el derecho de huelga; estos derechos están sujetos a las limitaciones y restricciones previstas en la ley, nadie podrá ser obligado a pertenecer a un sindicato (Protocolo adicional a la Convención Americana sobre derechos Humanos en materia de derechos Económicos, Sociales y Culturales “Protocolo de San Salvador", artículos 2, 6 punto 1 y 2, 7, 8, y 9). Finalmente se reconoce el derecho a la seguridad social.

\section{La protección de estos derechos}

Estos enfrentan el problema que Abramovich y Courtis (2014), señalan:

El reconocimiento de los derechos sociales como derechos plenos no se alcanzará hasta superar las barreras que impiden su adecuada justiciabilidad, entendida como la posibilidad de reclamar ante un juez o tribunal de justicia el cumplimiento al menos de algunas de las obligaciones que se derivan del derecho. De modo que, aunque un Estado cumpla habitualmente con la satisfacción de determinadas necesidades o intereses tutelados por un derecho social, no puede afirmarse que los beneficiados por la conducta estatal gozan de ese derecho como derecho subjetivo, hasta tanto verificar si la población se encuentra en realidad en condiciones de demandar judicialmente la prestación del Estado ante un eventual incumplimiento (p.3).

De lo que se deduce para lograr un efectivo reconocimiento y protección en el ámbito interno de un país de los derechos humanos sociales reconocidos en instrumentos internacionales, estos deben ser armonizados, así como también deben ser establecidos como derechos subjetivos, en donde se reconozca el derecho de la persona a exigir una sentencia que imponga su cumplimiento. 
Así Ventura Robles exjuez de la CIDH, ha señalado respecto de estos:

\begin{abstract}
En una relación laboral regida por el derecho privado, se debe tener en cuenta que existe una obligación de respeto de los derechos humanos entre particulares. Esto es, de la obligación positiva de asegurar la efectividad de los derechos humanos protegidos, que existe en cabeza de los Estados, se derivan efectos en relación con terceros (erga omnes). Dicha obligación ha sido desarrollada por la doctrina jurídica y, particularmente, por la teoría del Drittwirkung, según la cual los derechos fundamentales deben ser respetados, tanto por los poderes públicos como por los particulares en relación con otros particulares (Robles, 2004, p.127).
\end{abstract}

Por lo que se puede afirmar que estos, también imponen obligaciones al Estado, a saber:

a). - Armonización de su legislación interna al corpus juris internacional en derechos humanos, a través de medidas legislativas,

b). - Adopción de políticas públicas que hagan efectivo su cumplimiento.

Por su parte La Drittwirkung der Grundrechte ${ }^{2,}$ se origina en la comprensión de que los derechos fundamentales pueden ser lesionados también por sujetos privados, debería corresponder al ordenamiento jurídico establecer su defensa no solo frente a los actos del poder público sino, también, frente a los actos lesivos de los particulares (García, 2002, p.30).

Una preocupación creciente de todo el derecho, no solo el constitucional, es la limitación del abuso del poder. Las leyes laborales (...) que se engloban dentro de la rama del derecho social, que coexisten con el derecho público y privado y buscan protección de los derechos humanos, tanto a nivel vertical derecho social, derecho público, como horizontal derecho privado (Ferrer y Zaldivar, 2008, p.584). Por lo que la protección de los derechos humanos del trabajo y de la seguridad social si bien debe darse frente al Estado, también se sostiene que debe trasladarse esa obligación de respeto a las relaciones laborales entre particulares. Sobre este punto Barbagelata, ha señalado, como un criterio la "aplicabilidad de las normas constitucionales sobre derechos humanos a las relaciones entre los particulares" (Barbagelata, 2008, p.13).

Así tenemos que la protección de estos en las relaciones laborales entre particulares, es un tema que también ha sido tratado por la CIDH en la opinión consultiva 18/03, que se fundamenta en la doctrina jurídica denominada Drittwirkung, a partir de la cual la Corte ha establecido la obligación del Estado, que como legislador tiene la facultad de determinar, la legislación laboral aplicable a los particulares, por lo que puede ser responsable por su vulneración, cuando:

Una directriz o política estatal, respalde o favorezca la creación o mantenimiento de situaciones de discriminación en el ámbito laboral. Así la obligación de respeto prevista en el artículo 1.1 de la Convención Americana de Derechos Humanos, se concreta en tres vertientes respecto a los poderes públicos: Primera, como una responsabilidad directa en su carácter de empleador; Segunda, como obligación de adecuar su derecho interno a las disposiciones de la Convención y; Tercera, como responsabilidad subsidiaria cuando, a través de sus políticas públicas, fomente acciones y prácticas de terceros que consti-

2 Así tenemos que, este tipo de protección de los derechos fundamentales tuvo sus orígenes en Europa, primeramente, en Alemania en el año 1958, en donde el Tribunal Constitucional de dicho país, resolvió el famoso caso de Luth-Urteil, en este caso, el presidente del Club de prensa de Hamburgo, exhortaba a los ciudadanos alemanes para boicotear una película del cineasta Veit Harlan, después de haber sido demandado civilmente, Luth fue encontrado culpable del daño causado en perjuicio de Harlan (Schwabe, 2009). 
tuyan violaciones de derechos fundamentales (Barbagelata, 2008, p.123).

Por lo cual: La obligación impuesta por el respeto y garantía de los derechos humanos frente a terceros se basa también en que los Estados son los que determinan su ordenamiento jurídico, el cual regula las relaciones entre particulares y, por lo tanto, el derecho privado, por lo que deben también velar para que en esas relaciones privadas entre terceros se respeten los derechos humanos, ya que de lo contrario el Estado puede resultar responsable de la violación de los derechos (Robles, 2004, p.42).

Por tanto, se afirma que los Estados tienen también la obligación de legislar observando el cumplimiento de las disposiciones del corpus juris internacional en la materia, que hagan cumplir y garanticen los mismos a un en las relaciones laborales entre particulares.

Esta afirmación también encuentra sustento en el criterio de la:

Corte Europea de Derechos Humanos donde reconoció la aplicabilidad del Convenio Europeo para la Protección de los Derechos Humanos y de las Libertades Fundamentales a las relaciones interindividuales, cuando declaró que el Estado había violado dicho Convenio por haber impuesto una restricción a la libertad de asociación, que establecía que la pertenencia a determinados sindicatos era condición necesaria para que los peticionarios en el caso pudieran continuar siendo empleados de una empresa, puesto que la restricción impuesta no era necesaria en una sociedad democrática (López, 2008, p.207).

Por lo que el Estado, puede violar derechos humanos en las relaciones laborales, al imponer restricciones a derechos sindicales, como el obligar a los trabajadores a pertenecer a determinados sindicatos.

De ahí que los Estados están obligados a que sus ordenamientos jurídicos internos, cumplan y garanticen todos los derechos y libertades que surgen de las relaciones laborales, no solo estatales, también entre particulares.

Entre las obligaciones de los Estados de respeto, se incluyen la obligación de adecuar su derecho interno a las disposiciones de la Convención e instrumentos internacionales que contengan derechos humanos ya que el Estado puede generar una responsabilidad subsidiaria cuando, sus políticas públicas, fomente acciones y prácticas de terceros que constituyan violaciones de derechos fundamentales lo anterior se derivada del artículo 1.1 de la Convención Americana de los Derechos Humanos Pacto de San José de Costa Rica.

\section{Conclusiones}

Los derechos humanos han transitado de una dimensión filosófica (donde surgen), a una política (donde adquieren consenso) y finalmente a la jurídica (en donde se puede exigir su cumplimiento).

Estos derechos parten de la dignidad del trabajador, ya que, al iniciar, una relación laboral sea de carácter estatal o privada, tienen derecho a un salario remunerado, a la libertad sindical, a no realizar trabajo forzoso, a no ser discriminado, a contar con el derecho a formación profesional, a una protección social adecuada, aunado a los mecanismos que garanticen estos derechos.

Vienen a complementar los derechos individuales, teniendo como características comunes que ambos derechos requieren de la regulación estatal, para lograr su pleno cumplimiento.

Son varios los instrumentos internacionales que reconocen estos derechos. La CIDH ha interpretado 
estos instrumentos en el sentido de que se imponen obligaciones a los Estados de armonización de su legislación interna con derechos contenidos en instrumentos internacionales, legislando, adoptando políticas públicas, que hagan efectivo su cumplimiento, en las relaciones laborales tanto estatales como entre particulares.

Por tanto, los Estados tienen la obligación de armonizar sus ordenamientos internos al contenido del corpus juris internacional en derechos humanos, para lograr la plena eficacia en su protección, por lo que se hace necesario su reconocimiento como derechos públicos subjetivos.

\section{Referencias Bibliografica}

Alexy, Robert, (2000). Derechos sociales fundamentales. En Carbonell, Sánchez Miguel et al, (comp.), Derechos sociales y derechos de las minorías (pp. 67-85). Distrito Federal, México: Instituto de Investigaciones Jurídicas-Universidad Nacional Autónoma de México.

Álvarez, L., M. I. (2015). Teoría general y protección supranacional de los Derechos Humanos. Revista Urbe et lus, Buenos Aires, Número 14, invierno.

Barbagelata, H. H. (2008). Los principios de Derecho del Trabajo de segunda generación. IUS Labor no 1.

Carpizo, J. (2011). Los derechos humanos: naturaleza, denominación y características. Cuestiones constitucionales, Revista Mexicana de Derecho Constitucional, Número 25, julio-diciembre.

Carta Internacional Americana de Garantías Sociales. (1947).

Courtis C.; Abramovich, V. (2014). Apuntes sobre la exigibilidad judicial de los derechos sociales.

Corte Interamericana de Derechos Humanos. (1979).

Comisión de Derechos Humanos. (1948). Declaración Americana de los Derechos y Deberes del Hombre. ONU.

Comisión de Derechos Humanos. (1948). Declaración Universal de los Derechos Humanos. ONU.

Ferrajoli, L. (2004). Derechos y Garantías, La Ley del más débil (Traducción Ibáñez, A y Greppi, A). 4. ed. España. Trotta.

Ferrer M. G. E. y Zaldivar, L. L. A. (2008). Derechos Fundamentales y tutela constitucional, tomo IV, La Ciencia del Derecho Procesal Constitucional, estudios en homenaje a Héctor Fix-Zamudio en sus cincuenta años como investigador del derecho, UNAM-IIJUNAM-Instituto Mexicano de Derecho Procesal Constitucional-Marcial Pons, México.

García, P. V. (2002). La eficacia frente a particulares de los derechos fundamentales (la problemática de la Drittwirkung der Grundrechte), Pensamiento constitucional, año IX, número 9.

Kurczyn V. P. (s.f.). “Seguridad social”, pp.195-210. Recuperado de https://archivos.juridicas.unam.mx/www/ bjv/libros/6/2975/14.pdf

López P. J. M. (2008). Los derechos laborales en el Sistema Interamericano de Protección de Derechos Humanos: la protección de los derechos económicos, sociales y culturales. International Law: Revista Colombiana de Derecho Internacional, número 12, enero-junio.

Mendizábal B. G. y Jiménez L. M. (2012). Análisis de la dignidad del trabajador en el contexto de la globalización. El ejemplo de México. Revista chilena de derecho del trabajo y de la seguridad social, Vol. 3, No 6.

Pacto Internacional de Derechos Económicos Sociales y Culturales. (1966).

Pérez L. A. E. (2005) Los derechos sociales y su status normativo en la Constitución española. Documentación administrativa, Número 271-272. 
Protocolo adicional a la Convención Americana sobre derechos Humanos en materia de derechos Económicos, Sociales y Culturales "Protocolo de San Salvador".

Robles, M. E. V. (2004). Jurisprudencia de la Corte Inter-Americana de Derechos Humanos en materia de derechos económicos, sociales y culturales. Revista IIDH: Instituto Interamericano de Derechos Humanos, Madrid, no 40.

Ruiz M. Á. G. y Ruiz B. Á. E. (2017). La impugnación internacional de resoluciones jurisdiccionales en materia del derecho humano a la Seguridad Social. Revue Européenne du Droit Social, Volume XXXVI, Issue 3, Roumanie.

Salvioli, F. O. (s.f). El aporte de la Declaración Americana de 1948, para la protección internacional de los derechos humanos. pp. 1-16, http://www.derechoshumanos.unlp.edu.ar/assets/files/documentos/ el-aporte-de-la-declaracion-americana-de-1948-para-la-proteccion-internacional-de-los-derechos-humanos-fabian-salvioli.pdf

Sánchez C. A. (2008). Hacia una definición de los derechos fundamentales en el trabajo y su exigibilidad, La ciencia del derecho procesal constitucional. Estudios en homenaje a Héctor Fix-Zamudio en sus cincuenta años como investigador del derecho, T. XII, ministerio público, contenciosos administrativos y actualidad jurídica.

Schwabw, J. (2009). Jurisprudencia del Tribunal Constitucional Federal Alemán, extractos de las sentencias más relevantes, (Traducción. Anzola, M, Maus, $R$,) Fundación Konrad Adenauer Oficinas México. 
